\title{
Spectroscopic Properties and Dispersion Parameters of B2O3 - SiO2 - Bi2O3 - TiO2 - Y2O3 Glasses
}

Kh. S. shaaban ( $\square$ khamies1078@yahoo.com )

Chemistry Department, Faculty of Science, Al-Azhar University, P.O. 71524, Assiut, Egypt https://orcid.org/0000-0002-5969-3089

\section{Research Article}

Keywords: Glasses, Y203, spectroscopic, dispersion

Posted Date: March 30th, 2021

DOl: https://doi.org/10.21203/rs.3.rs-359567/v1

License: (a) (i) This work is licensed under a Creative Commons Attribution 4.0 International License.

Read Full License 
Spectroscopic properties and dispersion parameters of $\mathrm{B}_{2} \mathrm{O}_{3}-\mathrm{SiO}_{2}-\mathrm{Bi}_{2} \mathrm{O}_{3}-\mathrm{TiO}_{2}-$

\section{$\mathrm{Y}_{2} \mathrm{O}_{3}$ glasses}

Kh. S. Shaaban ${ }^{1, *}$

${ }^{1}$ Chemistry Department, Faculty of Science, Al-Azhar University, P.O. 71524, Assiut, Egypt.

\section{ABSTRACT}

Glasses with the chemical formula $52 \mathrm{~B}_{2} \mathrm{O}_{3}-12 \mathrm{SiO}_{2}-26 \mathrm{Bi}_{2} \mathrm{O}_{3}-(10-x) \mathrm{TiO}_{2}-x \mathrm{Y}_{2} \mathrm{O}_{3}$, : $(0 \leq x \geq 10)$, the melt-quench method was used to prepare this glass system. The purpose of this article is to investigate the spectroscopic features of these glasses. The nature of the glass system has been investigated using X-ray diffraction analysis. In the current article, the molar volume acquired decreased while the density and refractive index increased. In the current article, $\mathrm{Y}_{2} \mathrm{O}_{3}$ plays an important role and impacts the spectroscopic characteristics of the samples accordingly. For all the present glasses, the optical bandgap is found to be in the semiconducting range. The optical bandgap enhances as $\mathrm{Y}_{2} \mathrm{O}_{3}$ rises, while Urbach energy reduces. Molar Refractivity, molar polarization, polarizability, and optical basicity decrease with increasing $\mathrm{Y}_{2} \mathrm{O}_{3}$ content. Wemple and Didomenico principles were used for calculated the $E o$ and $E d$ dispersion. The significance of the $\mathrm{Y}_{2} \mathrm{O}_{3}$ modifier in the glass system signifies proved.

Keywords: Glasses; $\mathrm{Y}_{2} \mathrm{O}_{3}$, spectroscopic, dispersion

*Corresponding Authors: Emails: khamies1078@yahoo.com, 


\section{Introduction}

Due to the importance of glass materials containing many transition metal ions (TMI) for many applications, these glasses have existed intersected over the past few years. In specific, the glass based on $\mathrm{B}_{2} \mathrm{O}_{3}$ and $\mathrm{SiO}_{2}$ has become common among a wide variety of glass systems, keeping in mind its glass status, transparency, and a variety of physical and chemical properties. The B element can transform its coordination number between 3 and 4 with oxygen supplying by modification of metal cations [1-5]. Due to their unique properties such as hardness, transparency, UV-transmission ability, and corrosion resistance, $\mathrm{SiO}_{2}-\mathrm{B}_{2} \mathrm{O}_{3}$ glasses were investigated for many years. $\mathrm{B}_{2} \mathrm{O}_{3}-\mathrm{SiO}_{2}$ glass modified with $\mathrm{Bi}_{2} \mathrm{O}_{3}$ is characterized by its excellent optical, mechanical, radiation, and electrical properties [5-12].

The physical characteristics of the glass change based on its formulation and can be linked with the network structures and interatomic forces. Glasses with higher levels of bridging oxygen (BOs) have a more compact glass framework and high elastic moduli. Introducing $\mathrm{Y}_{2} \mathrm{O}_{3}$ to $\mathrm{SiO}_{2}-\mathrm{B}_{2} \mathrm{O}_{3}$ glasses provide chemical stability durability, a vast compositional variety of glass forming, and increased transmission with promising properties reported. The presence of trivalent oxide like $\mathrm{Y}_{2} \mathrm{O}_{3}$ in borosilicate glass exhibits dual nature as former or intermediate in the glass network. These glasses obtained noticed to withstand atmospheric moisture and are accept a good quantity of doping transition metal (TM) or rareearth (REs) [13-17].

Glasses doped intermediate oxides such as $\mathrm{TiO}_{2}$ and $\mathrm{Y}_{2} \mathrm{O}_{3}$ have specific mechanical and optical characteristics such as hardness, elastic moduli, and higher refractive index [1521]. It is also significant to observe that the inclusion of $\mathrm{Y}_{2} \mathrm{O}_{3}$ improves the capability of UV transmission, enhances thermal stability and chemical durability. The emergence of $\mathrm{Y}_{2} \mathrm{O}_{3}$ into the glass network improved the glass's mechanical, thermal, and crystallization characteristics. 
Because of their excellent conductivity, these samples in ionic terms, it is probable to use them in UV optics, solid-state batteries, and radiation protection. These glasses have a higher refractive index and less photon energy than other glasses. The significant development of $\mathrm{B}_{2} \mathrm{O}_{3}-\mathrm{SiO}_{2}-\mathrm{Bi}_{2} \mathrm{O}_{3}-\mathrm{TiO}_{2}-\mathrm{Y}_{2} \mathrm{O}_{3}$ glasses is extremely important in both science and technology. The creativity of this research paper is reflected in the structural, and optical characteristics of $\mathrm{B}_{2} \mathrm{O}_{3}-\mathrm{SiO}_{2}-\mathrm{Bi}_{2} \mathrm{O}_{3}-\mathrm{TiO}_{2}$ glass undoped and doped with $\mathrm{Y}^{+3}$ ions.

\section{Methodology}

Five glass samples in Table 1 with the nominal compositions $52 \mathrm{~B}_{2} \mathrm{O}_{3}-12 \mathrm{SiO}_{2}-$ $26 \mathrm{Bi}_{2} \mathrm{O} 3-\mathrm{TiO}_{2}-\mathrm{Y}_{2} \mathrm{O}_{3}$, prepared using the solid-state conventional method. By melting together specific weights of $\mathrm{B}_{2} \mathrm{O}_{3}$ in the form of $\mathrm{H}_{3} \mathrm{BO}_{4}$ (Merck), $\mathrm{SiO}_{2}$ (Aldrich), $\mathrm{Bi}_{2} \mathrm{O}_{3}$ (Merck), $\mathrm{TiO}_{2}$ (Merck), and $\mathrm{Y}_{2} \mathrm{O}_{3}$ (Merck) in an open porcelain crucible. $\mathrm{H}_{3} \mathrm{BO}_{4}$ converted into $\mathrm{B}_{2} \mathrm{O}_{3}$ after the $\mathrm{H} 2 \mathrm{O}$ evaporation process throughout the melting in porcelain crucibles. Thus, it is possible to estimate the required amount of oxide to match the chemical formula used by knowing the molecular weight of $\mathrm{H}_{3} \mathrm{BO}_{4}$, and $\mathrm{B}_{2} \mathrm{O}_{3}$. The porcelain crucible with the blend was kept at 650 ${ }^{\circ} \mathrm{C}$ for 45 minutes to decrease the tendency to volatilize. The furnace temperature programmed to rise to the melting temperature at $1150{ }^{\circ} \mathrm{C}$ and kept for 50 minutes. To remove internal stresses, the melting glass was cast in a clean stainless-steel mold and annealed at $400{ }^{\circ} \mathrm{C}$.

The status of manufactured glasses was checked using a Philips X-ray diffractometer (model PW/1710). Densities of samples quantified by Archimedes method. $\rho=\rho_{0}\left(\frac{M}{M-M_{1}}\right)$ where $M$ and $M_{l}$ are the weights of samples in air and fluid, the glass density is $\rho$ and the density of toluene is $\rho_{0}\left(0.865 \mathrm{~g} \cdot \mathrm{cm}^{-3}\right)$. Molar volume can evaluate as $V_{m}=\frac{M}{\rho}$ where M average molecular weight of the glasses. The optical spectra were obtained at wavelengths ranging from 2700 to $200 \mathrm{~nm}$ using a (JASCO V-670 spectrophotometer - Japan).

\section{Results and Discussions}

\subsection{XRD}


XRD characteristic of $\mathrm{B}_{2} \mathrm{O}_{3}-\mathrm{Bi}_{2} \mathrm{O}_{3}-\mathrm{SiO}_{2}-\mathrm{TiO}_{2}-\mathrm{Y}_{2} \mathrm{O}_{3}$ glass with a wide hollow band at $2 \theta^{\circ}$ between $\left(20^{\circ}-30^{\circ}\right)$ demonstrated in Fig.1, which signifies the amorphous status of the glass. The width of the small mound differs from one sample to another but is not no indications of the crystalline phases have displayed in all the glasses.

\subsection{Physical Studies}

Different factors, such as chemical constituents and internal structure have affected the density of $52 \mathrm{~B}_{2} \mathrm{O}_{3}-12 \mathrm{SiO}_{2}-26 \mathrm{Bi}_{2} \mathrm{O}_{3}-(10-x) \mathrm{TiO}_{2}-x \mathrm{Y}_{2} \mathrm{O}_{3}$, where $x:(0 \leq x \geq 10)$ glass system. Its values are in the range $4.213-5.07 \mathrm{~g} / \mathrm{cm}^{3}$ for different glass compositions and follow a linear trend. The density of these samples increases with an increment in the content of $\mathrm{Y}_{2} \mathrm{O}_{3}$. This observation because of the high $\mathrm{Y}_{2} \mathrm{O}_{3}$ density $\left(5.03 \mathrm{~g} / \mathrm{cm}^{3}\right)$ relative to $\mathrm{TiO}_{2}\left(4.23 \mathrm{~g} / \mathrm{cm}^{3}\right)$ and the high $\mathrm{Y}_{2} \mathrm{O}_{3}$ atomic mass (225.81) relative to $\mathrm{TiO}_{2}$ (79.866). The emergence of $\mathrm{Y}_{2} \mathrm{O}_{3}$ in a glass matrix enhances the structural network by raising the oxygen level, resulting in the transformation of $\mathrm{BO}_{3}$ into $\mathrm{BO}_{4}$ units, and may also another reason lead to an increase in glass density. In the science of glass, the molar volume also plays an important role. The reduction in molar volume could be related to the formation of bridging oxygens that reduce the voids within the configuration. The density and molar volume of $\mathrm{B}_{2} \mathrm{O}_{3}-\mathrm{Bi}_{2} \mathrm{O}_{3}-\mathrm{SiO}_{2}-\mathrm{TiO}_{2}-\mathrm{Y}_{2} \mathrm{O}_{3}$ glasses are exemplified in Fig. 2.

Field strength $F i$ of these samples were evaluated by:

$$
\begin{aligned}
& F i=\frac{m}{r_{p}^{2}} \\
& r p=\frac{1}{2}\left(\frac{\pi}{6 N}\right)^{\frac{1}{3}}
\end{aligned}
$$

Where $m$ average coordination number, and $r p$ polaron radius.

The molar refractivity $R_{m}$ as bandgap $E_{\text {opt }}$, molar polarizability $\left(\propto_{m}\right)$, and Reflection loss $R_{L}$, were evaluated by: 
$R_{m}=\operatorname{Vm}(1-\sqrt{\text { Eopt. } / 20})$

$\propto_{m}=\left(\frac{3}{4 \pi N}\right) R_{m}$

$R_{L}=\left(\frac{R_{m}}{V m}\right)$

The criterion for metallization, electronegativity $(\chi)$, electron polarizability $\propto^{\circ}$, and optical basicity $\wedge$ predicted as:

$M=1-\frac{R_{m}}{V m}$

$\chi=0.2688 E_{\text {opt }}$.

$\propto^{\circ}=-0.9 \chi+3.5$

$\wedge=-0.5 \chi+1.7$

Because of the decrease in molar volume, the values of $\left(R_{m}\right)\left(\propto_{m}\right)$ and $\left(R_{L}\right)$ decrease with $\mathrm{Y}^{+3}$ while $M$ increased. As $\mathrm{Y}^{+3}$ increases, do the electronegativity $(\chi)$ values increase. $\alpha^{\circ}$ and $\wedge$ have the inverse value of $(\chi)$ so, $\propto^{\circ}$ and $\wedge$ decrease with $\mathrm{Y}^{+3}$. These data can signify recorded in Table 2.

\subsection{Optical studies}

Optical absorption spectra are one of the most useful tools for determining the electronic structure of glasses [22-25]. Fig. 3 demonstrates the absorption (A) and transmittance (T) of glass system. These observations were used to evaluate the optical band gap and Urbach energy in the 200-2700 nm. The absorption coefficient of these samples is illustrated in Fig. 4.

$\propto=(2.303 \mid d) * A \quad(10)$

Where $d$ thickness of glass sample. As a result, $\mathrm{Y}_{2} \mathrm{O}_{3}$ is to take responsibility for enhances of BO.

\subsubsection{Calculations of optical bandgap (Eopt.) and Urbach energy Eu}

According to Tauc's concept [26], bandgap energies for direct and indirect transitions are determined by: 


$$
\alpha h v=C\left(h v-E_{o p t}\right)^{s}
$$

where $\mathrm{C}$ is a transition probability parameter and $s$ is an index with values of 0.5 , and 2 for direct allowed and indirectly allowed. Figs. 5 and 6 demonstrate the relationship between $(\alpha h v)^{1 / 2},(\alpha h v)^{2}$, and $(h v)$ for as-prepared glasses. $E_{o p t}^{\text {dir }}$, and $E_{\text {opt. }}^{\text {indir }}$ for the investigated glasses were calculated from the intercepts of the straight as Figs. 5 and 6. Table 2 displays the obtained data values. We realize that adding $\mathrm{Y}_{2} \mathrm{O}_{3}$ to the glass enhances the bandgap energy. The glassfree $\mathrm{Y}_{2} \mathrm{O}_{3}(\mathrm{G} 1)$ is characterized by Eopt. $=2.08$, and $2.12 \mathrm{eV}$, but with the lower concentration of $\mathrm{Y}_{2} \mathrm{O}_{3} \mathrm{G} 2$ (Eopt.=2.2, and 2.26, the Eopt. starts increasing until high content of $\mathrm{Y}_{2} \mathrm{O}_{3} \mathrm{G} 5$ $($ Eopt.$=2.74$, and $2.8 \mathrm{eV})$. This increasing trend in bandgap may be associated with an increase in bridging oxygen (BO) in the samples. With a $\mathrm{TiO}_{2}$ replaced by $\mathrm{Y}_{2} \mathrm{O}_{3}$, because of an increasing trend in bridging oxygens (BOs), structural units, and interconnection of modifier oxide tetrahedral increment, while non-bridging oxygens (NBOs) reduce. It denotes a reduction in the number of donor centers in the glass network, resulting in an increase in optical bandgap energy and, as a result, a shift in the absorption edge to a lower wavelength. As a result, may attribute the increase in Eopt. to the addition of $\mathrm{Y}_{2} \mathrm{O}_{3}$. Because of the addition of $\mathrm{Y}_{2} \mathrm{O}_{3}$ to the glass matrix, $\mathrm{YO}_{6}$ and $\mathrm{YO}_{4}$ units may alternate with $\mathrm{BO} 4$ in the glass, resulting in a decrease in the number of bonding defects and NBOs.

Urbach energy $E_{u}$ of samples has predicted as:

$$
\propto_{0} \exp \left(\frac{h v}{E_{u}}\right)
$$

Figure 7 exemplifies the logarithm of absorption coefficient as a function of energy for determining the Urbach energy $\left(E_{u}\right) . E_{u}$ owns the differing correlation described among their Eopt. values. As shown in Fig. 8, and table 2 the Urbach energy decreases while the bandgap energy increases as $\mathrm{Y}_{2} \mathrm{O}_{3}$ rises. This is attributed to the fact that adding $\mathrm{Y}_{2} \mathrm{O}_{3}$ into the glass matrix tends to cause the creation of bridging oxygens, which reduces disorder.

\subsubsection{Refractive index $\left(n_{D}\right)$}


$n_{D}$ of manufacturing glasses calculated as:

$$
n=\frac{(1-R)^{2}+k^{2}}{(1+R)^{2}+k^{2}}
$$

where $k=\alpha \lambda / 4 \pi$, and $R$ reflectance of glass

samples shown in Fig. 9. $n_{D}$ of synthesized glasses is shown in Fig.10, and it was discovered that the $n_{D}$ of the studied glasses rises as density tends to increase. It confirmed that there is a significant correlation between density and refractive index, i.e., the higher $n_{D}$ values are the denser in this article.

\subsubsection{Dispersion parameters}

Molar Refractivity $R_{m}$, molar polarization $\propto_{m}$, polarizability, and optical basicity $(\wedge)$ given by:

$$
\begin{aligned}
& R_{m}=\left\langle n^{2}-1 \mid n^{2}+2\right\rangle V m \\
& \propto_{m}=(3 \mid 4 \pi N) R_{m} \\
& \propto_{0}^{2-}=\frac{\left[\frac{V m}{2.52}\left(\frac{n^{2}-1}{n^{2}+2}\right)-\sum \propto_{c a t}\right]}{N_{o}^{2-}} \\
& \Lambda=1.67\left(1-\frac{1}{\alpha_{0}^{2-}}\right)
\end{aligned}
$$

These concepts are exemplifying in Figs. 9, 10, and 11. According to the outcomes of these glasses, these constructs appear to decrease with increasing $\mathrm{Y}_{2} \mathrm{O}_{3}$ content. Molar polarizability is proportional to molar volume, according to Lorentz-Lorenz principles. As a result of the change in molar volume denoting that these samples are less polarized with the increase in $\mathrm{Y}_{2} \mathrm{O}_{3}$, the $R_{m}, \propto_{0}^{2-}$, and $\Lambda$ of glasses decrease.

Wemple and Didomenico calculated the Eo and Ed dispersion [27-30].

$$
n^{2}-1=\frac{E_{0} E_{d}}{E_{0}^{2}-E^{2}}
$$

Figures 12 show $\left(\mathrm{n}^{2}-1\right)^{-1}$ with $\lambda^{-2}, E o$ and $E d$ predicted from the slope and intercept. It was stated that as $\mathrm{Y}_{2} \mathrm{O}_{3}$ increased, so did Eo and Ed. Eopt, $(n o), \varepsilon_{\infty},(\lambda o)$, and (So) calculated as: 


$$
\begin{aligned}
& \text { Eopt }=\frac{E_{d}}{2} \\
& n_{0}=\sqrt{1+\frac{E_{d}}{E_{0}}} \\
& \varepsilon_{\infty}=n_{0}^{2} \\
& n^{2}-1=\frac{S_{0} \lambda_{0}^{2}}{1-\left(\frac{\lambda_{0}}{\lambda}\right) 2}
\end{aligned}
$$

Where Eopt, $(n o), \varepsilon_{\infty},(\lambda o)$, and $(S o)$ are bandgap, static refractive index, oscillator wavelength, and oscillator strength. These components are found in Table 3. It was stated that as $\mathrm{Y}_{2} \mathrm{O}_{3}$ increased, these components increased.

Figures $15 \& 16$ demonstrate a refractive index (direct and indirect) according to [31-35]. The linear and non-linear bandgaps caused a small deviation in the (n). Moreover, dielectric and the static dielectric constant $(\varepsilon \boldsymbol{c o}$, and $\varepsilon \infty)$ were calculated as follows:

$$
\begin{aligned}
& \boldsymbol{\varepsilon} \boldsymbol{o}=-33.26876+78.61805 E_{g}-45.70795 E_{g}^{2}+8.32449 E_{g}^{3} \\
& \varepsilon \infty=\mathrm{n}_{\mathrm{AV}}^{2} \quad(24)
\end{aligned}
$$

Tables $4 \& 5$ show various optical constraints $(\varepsilon \infty),\left(\varepsilon_{0}\right), \chi^{(1)},\left(\chi^{(3)}\right)$ and $\left(n_{2}\right)$ as a function of linear and non-linear Eopt.

\section{Conclusions}

The influence of varying $\mathrm{Y}_{2} \mathrm{O}_{3}$ content on the structure of spectroscopic properties of yttrium bismuth titanate borosilicate glasses with the form $52 \mathrm{~B}_{2} \mathrm{O}_{3}-12 \mathrm{SiO}_{2}-26 \mathrm{Bi}_{2} \mathrm{O}_{3}-(10-x) \mathrm{TiO}_{2}$ - $x \mathrm{Y}_{2} \mathrm{O}_{3}$, where $x=0,2,6,8$, and $10 \mathrm{~mol} \%$ have illustrated in this investigation. XRD measurements evaluated the amorphous status of the glasses. In the current article, the molar volume acquired is reduced while the density is increased. In the current article, $\mathrm{Y}_{2} \mathrm{O}_{3}$ plays an important role and impacts the spectroscopic characteristics of the samples accordingly. The acquired values for optical bandgap (Eopt.) indirect and direct, and Urbach energy $\left(E_{u}\right)$, demonstrated that increasing the bridging oxygens in the glass network leads to an increase in 
Eopt. and a decrease in $E_{u}$, which is connected to decreasing disorder. Molar Refractivity, molar polarization, polarizability, and optical basicity decrease with increasing $\mathrm{Y}_{2} \mathrm{O}_{3}$ content. Wemple and Didomenico principles were used for calculated the $E o$ and $E d$ dispersion. 
Author contributions: Kh. S. Shaaban: performing, XRD, mechanical measurements and analysis, Writing-review, writing the manuscript, Methodology, Software, and writing discussion.

\section{Acknowledgments:}

Availability of data and material: My manuscript and associated personal data will be shared with Research Square for the delivery of the author dashboard.

Compliance with ethical standards: The manuscript has not been published elsewhere and has not been submitted simultaneously for publication elsewhere.

Conflict of interest: The authors declare that they have no conflict of interest.

Declaration of Competing Interest: The authors declare that they have no known competing financial interests or personal relationships that could have appeared to influence the work reported in this paper.

Funding statement: There are currently no Funding Sources on the list

Consent to participate: The authors consent to participate.

Consent for Publication: The author's consent for publication. 


\section{References}

[1] Shaaban, K. S., Abo-Naf, S. M., \& Hassouna, M. E. M. Physical and Structural Properties of Lithium Borate Glasses Containing $\mathrm{MoO}_{3}$. Silicon 11, 2421-2428, (2019). DOI:10.1007/s12633-016-9519-4

[2] El-Rehim, A.F.A., Shaaban, K.S. (2021), Influence of $\mathrm{La}_{2} \mathrm{O}_{3}$ content on the structural, mechanical, and radiation-shielding properties of sodium fluoro lead barium borate glasses. J Mater Sci: Mater Electron. https://doi.org/10.1007/s10854-020-05204-7

[3] Shaaban, K. S., Abo-naf S. M., Abd Elnaeim, A. M., \& Hassouna, M. E. M. Studying effect of $\mathrm{MoO}_{3}$ on elastic and crystallization behavior of lithium diborate glasses. Applied Physics A, 123(6) 457, (2017). DOI:10.1007/s00339-017-1052-9

[4] Rao, L. S., Reddy, M. S., Rao, D. K., \& Veeraiah, N. Influence of redox behavior of copper ions on dielectric and spectroscopic properties of $\mathrm{Li}_{2} \mathrm{O}-\mathrm{MoO}_{3}-\mathrm{B}_{2} \mathrm{O}_{3}: \mathrm{CuO}$ glass system. SolidState Sciences, 11(2), 578-587. (2009). DOI: 10.1016/j.solidstatesciences.2008.06.022 [5] Abd-Allah, W.M., Saudi, H.A., Shaaban, K.S. et al. Investigation of structural and radiation shielding properties of $40 \mathrm{~B}_{2} \mathrm{O}_{3}-30 \mathrm{PbO}-(30-x)$ BaO- $x \mathrm{ZnO}$ glass system. Appl. Phys. A 125, 275 (2019). https://doi.org/10.1007/s00339-019-2574-0

[6] Saudi, H.A., Abd-Allah, W.M. \& Shaaban, K.S. Investigation of gamma and neutron shielding parameters for borosilicate glasses doped europium oxide for the immobilization of radioactive waste. J Mater Sci: Mater Electron 31, 6963-6976 (2020). https://doi.org/10.1007/s10854-020-03261-6

[7] Somaily, H.H., Shaaban, K.S., Makhlouf, S.A. et al. Comparative Studies on Polarizability, Optical Basicity and Optical Properties of Lead Borosilicate Modified with Titania. J Inorg Organomet Polym (2020). https://doi.org/10.1007/s10904-020-01650-2 
[8] Wahab, E. A. A., \& Shaaban, K. S. Effects of $\mathrm{SnO}_{2}$ on spectroscopic properties of borosilicate glasses before and after plasma treatment and its mechanical properties. Materials Research Express, 5(2), 025207, (2018). https://doi.org/10.1088/2053-1591/aaaee8

[9] Koubisy, M.S.I., Shaaban, K.S., Wahab, E.A.A. et al. (2021), Synthesis, structure, mechanical and radiation shielding features of $50 \mathrm{SiO}_{2}-(48+\mathrm{X}) \quad \mathrm{Na}_{2} \mathrm{~B}_{4} \mathrm{O}_{7}-(2-\mathrm{X})$ $\mathrm{MnO}_{2}$ glasses. Eur. Phys. J. Plus 136, 156, https://doi.org/10.1140/epjp/s13360-021-01125-4 [10] E.A. Abdel Wahab, M.S.I. Koubisy, M.I. Sayyed, K.A. Mahmoud, A.F. Zatsepin, Sayed A. Makhlouf, Shaaban, Kh.S. (2021), Novel borosilicate glass system: $\mathrm{Na}_{2} \mathrm{~B}_{4} \mathrm{O}_{7}-\mathrm{SiO}_{2}-\mathrm{MnO}_{2}$ Synthesis, average electronics polarizability, optical basicity, and gamma-ray shielding features, Journal of Non-Crystalline Solids, 553,120509, doi.org/10.1016/j.jnoncrysol.2020.120509 [11] El-Rehim, A.F.A., Zahran, H.Y., Yahia, I.S. et al. (2020). Physical, Radiation Shielding and Crystallization Properties of $\mathrm{Na}_{2} \mathrm{O}-\mathrm{Bi}_{2} \mathrm{O}_{3}-\mathrm{MoO}_{3}-\mathrm{B}_{2} \mathrm{O}_{3}-\mathrm{SiO}_{2} \mathrm{Fe}_{2} \mathrm{O}_{3}$ Glasses. Silicon, doi.org/10.1007/s12633-020-00827-1

[12] Shaaban, K.S., Yousef, E.S., Abdel Wahab, E.A. et al. (2020). Investigation of Crystallization and Mechanical Characteristics of Glass and Glass-Ceramic with the Compositions $x \mathrm{Fe}_{2} \mathrm{O}_{3}-35 \mathrm{SiO}_{2}-35 \mathrm{~B}_{2} \mathrm{O}_{3}-10 \mathrm{Al}_{2} \mathrm{O}_{3}-(20-x) \quad \mathrm{Na}_{2} \mathrm{O}$. J. of Materi Eng and Perform. https://doi.org/10.1007/s11665-020-04969-6

[13] El-Rehim, A.F.A., Zahran, H.Y., Yahia, I.S. et al. Structural, Elastic Moduli, and Radiation Shielding of $\mathrm{SiO}_{2}-\mathrm{TiO}_{2}-\mathrm{La}_{2} \mathrm{O}_{3}-\mathrm{Na}_{2} \mathrm{O}$ Glasses Containing $\mathrm{Y}_{2} \mathrm{O}_{3}$. J. of Materi Eng and Perform (2021). https://doi.org/10.1007/s11665-021-05513-w

[14] El-Sharkawy, R. M., Shaaban, K. S., Elsaman, R., Allam, E. A., El-Taher, A., \& Mahmoud, M. E. (2020). Investigation of mechanical and radiation shielding characteristics of novel glass systems with the composition $\mathrm{xNiO}-20 \mathrm{ZnO}-60 \mathrm{~B}_{2} \mathrm{O}_{3}-(20-\mathrm{x}) \mathrm{CdO}$ based on nano metal oxides. Journal of Non-Crystalline Solids, 528,119754 doi: 10.1016/j.jnoncrysol.2019.119754 
[15] Shaaban, K.S., Zahran, H.Y., Yahia, I.S. et al. (2020), Mechanical and radiation-shielding properties of $\mathrm{B}_{2} \mathrm{O}_{3}-\mathrm{P}_{2} \mathrm{O}_{5}-\mathrm{Li}_{2} \mathrm{O}-\mathrm{MoO}_{3}$ glasses. Appl. Phys. A 126, (10), 804. https://doi.org/10.1007/s00339-020-03982-9

[16] Shaaban, K.S., Koubisy, M.S.I., Zahran, H.Y. et al. (2020). Spectroscopic Properties, Electronic Polarizability, and Optical Basicity of Titanium-Cadmium Tellurite Glasses Doped with Different Amounts of Lanthanum. J Inorg Organomet Polym. https://doi.org/10.1007/s10904-020-01640-4

[17] El-Rehim, A.A., Zahran, H., Yahia, I. et al. (2020). Radiation, Crystallization, and Physical Properties of Cadmium Borate Glasses. Silicon https://doi.org/10.1007/s12633-02000798-3

[18] Shaaban, K.S., Yousef, E.S., Mahmoud, S.A. et al. (2020). Mechanical, Structural and Crystallization Properties in Titanate Doped Phosphate Glasses. J Inorg Organomet. Polym https://doi.org/10.1007/s10904-020-01574-X

[19] El-Rehim, A.F.A., Zahran, H.Y., Yahia, I.S. et al. (2020). Physical, Radiation Shielding and Crystallization Properties of $\mathrm{Na}_{2} \mathrm{O}_{-}-\mathrm{Bi}_{2} \mathrm{O}_{3-} \quad \mathrm{MoO}_{3}-\mathrm{B}_{2} \mathrm{O}_{3}{ }^{-} \quad \mathrm{SiO}_{2-}$ $\mathrm{Fe}_{2} \mathrm{O}_{3}$ Glasses. Silicon https://doi.org/10.1007/s12633-020-00827-1

[20] Koubisy, M.S.I., Shaaban, K.S., Wahab, E.A.A. et al. (2021), Synthesis, structure, mechanical and radiation shielding features of $50 \mathrm{SiO}_{2}-(48+\mathrm{X}) \quad \mathrm{Na}_{2} \mathrm{~B}_{4} \mathrm{O}_{7}-(2-\mathrm{X})$ $\mathrm{MnO}_{2}$ glasses. Eur. Phys. J. Plus 136, 156, https://doi.org/10.1140/epjp/s13360-021-01125-4 [21] El-Rehim, A.F.A., Shaaban, K.S. Influence of $\mathrm{La}_{2} \mathrm{O}_{3}$ content on the structural, mechanical, and radiation-shielding properties of sodium fluoro lead barium borate glasses. $J$ Mater Sci: Mater Electron 32, 4651-4671 (2021). https://doi.org/10.1007/s10854-020-05204-7

[22] Shaaban, K.S., Wahab, E.A.A., Shaaban, E.R. et al. (2020). Electronic polarizability, optical basicity and mechanical properties of aluminum lead phosphate glasses. Opt Quant Electron 52, 125 https://doi.org/10.1007/s11082-020-2191-3 
[23] Shaaban, K.S., Wahab, E.A.A., Shaaban, E.R. et al. (2020). Electronic Polarizability, Optical Basicity, Thermal, Mechanical and Optical Investigations of $\left(65 \mathrm{~B}_{2} \mathrm{O}_{3}-30 \mathrm{Li}_{2} \mathrm{O}-\right.$ $5 \mathrm{Al}_{2} \mathrm{O}_{3}$ ) Glasses Doped with Titanate. Journal of Elec Materi 49, 2040-2049.

\section{https://doi.org/10.1007/s11664-019-07889-x}

[24] Singh S., G. Kalia and K. Singh, (2015), Effect of Intermediate Oxide $\left(\mathrm{Y}_{2} \mathrm{O}_{3}\right)$ on Thermal, Structural and Optical Properties of Lithium Borosilicate Glasses, Mol. Struct., 1086, 239-245. https://doi.org/10.1016/j.molstruc.2015.01.031

[25] Rao, P. N., Reddy, M. C. S., Reddy, A. P., Kumar, E. R., \& Rao, B. A. (2021). Optical and dielectric studies of $\mathrm{CdI}_{2}$-doped silver borotelurate glass system. Journal of Materials Science: Materials in Electronics. J Mater Sci: Mater Electron, 32:806-817 doi:10.1007/s10854-020-04859-6

[26] Dolgonos A., T.O. Mason, K.R. Poeppelmeier, (2016), Direct optical band gap measurement in polycrystalline semiconductors: a critical look at the Tauc method, J. Solid State Chem 240 ,43-48, https://doi.org/10.1016/j.jssc.2016.05.010.

[27] Wemple, S.H. and DiDomenico Jr., M. (1971) Behavior of the Electronic Dielectric Constant in Covalent and Ionic Materials. Physical Review B, 3, 1338-1351. http://dx.doi.org/10.1103/PhysRevB.3.1338

[28] Abdel-Aziz, M. M., Yahia, I. S., Wahab, L. A., Fadel, M., \& Afifi, M. A. Determination and analysis of dispersive optical constant of $\mathrm{TiO}_{2}$ and $\mathrm{Ti}_{2} \mathrm{O}_{3}$ thin films. Appl. Sur. Sci., 252(23), 8163-8170, (2006). DOI: 10.1016/j.apsusc.2005.10.040

[29] Abdel-Aziz, M. M., Metwally E.G. El-, Fadel M., Labib H.H., Afifi, M. A., Optical properties of amorphous Ge-Se-Tl system films, Thin Solid Films 386, 99 - 104, (2001). https://doi.org/10.1016/S0040-6090(01)00765-9 
[30] Chiad S. S., Habubi, N. F., Abass W. H., Abdul Allah M. H., Effect of thickness on the optical and dispersion parameters of $\mathrm{Cd}_{0.4} \mathrm{Se}_{0.6}$ thin films, J. of opt. elec. and adv. mat., 18, (910), 822 (2016).

[31] Moss, T. S. (1985). Relations between the Refractive Index and Energy Gap of Semiconductors. Physica Status Solidi (b), 131(2), 415-427. doi:10.1002/pssb.2221310202 [32] Ravindra, N. M. (1981). Energy gap-refractive index relation — some observations. Infrared Physics, 21(5), 283-285. doi:10.1016/0020-0891(81)90033-6

[33] Gupta, V. P., \& Ravindra, N. M. (1980). Comments on the Moss Formula. Physica Status Solidi (b), 100(2), 715-719. doi:10.1002/pssb.2221000240

[34] Anani M., Mathieu C., Lebid S., Amar Y., Chama Z. and Abid H., (2008). Model for calculating the refractive index of a III-V semiconductor, Comput. Mater. Sci 41, 570-757, [35] Kumar V. and Singh J. K., (2010). Model for calculating the refractive index of different materials, Ind. J. Pure and Appl. Phys., 48, 571- 574,

[36] Hervé, P., \& Vandamme, L. K. J. (1994). General relation between refractive index and energy gap in semiconductors. Infrared Physics \& Technology, 35(4), 609-615. doi:10.1016/1350-4495(94)90026-4 
Figures

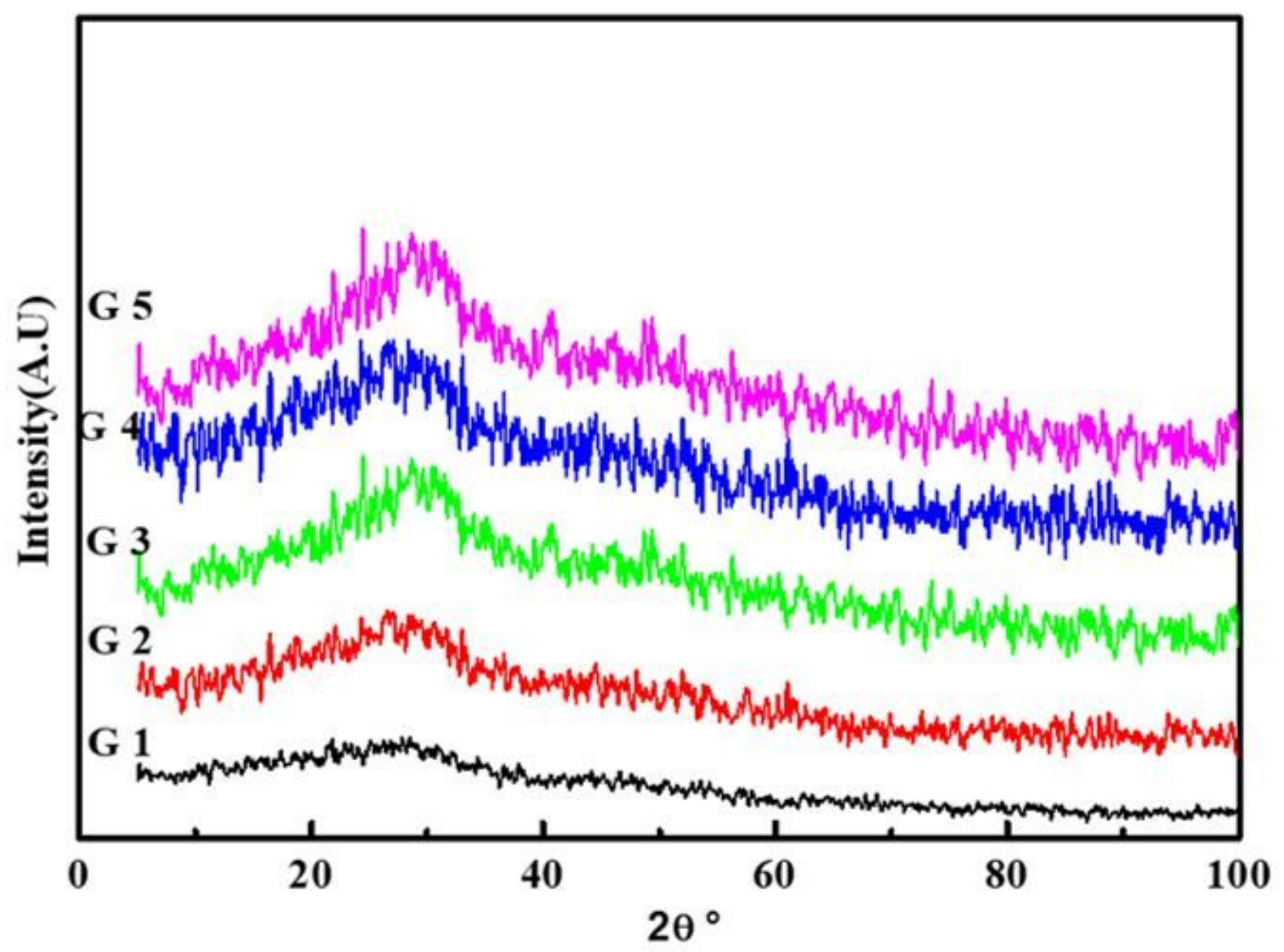

Figure 1

XRD of the studied glasses. 


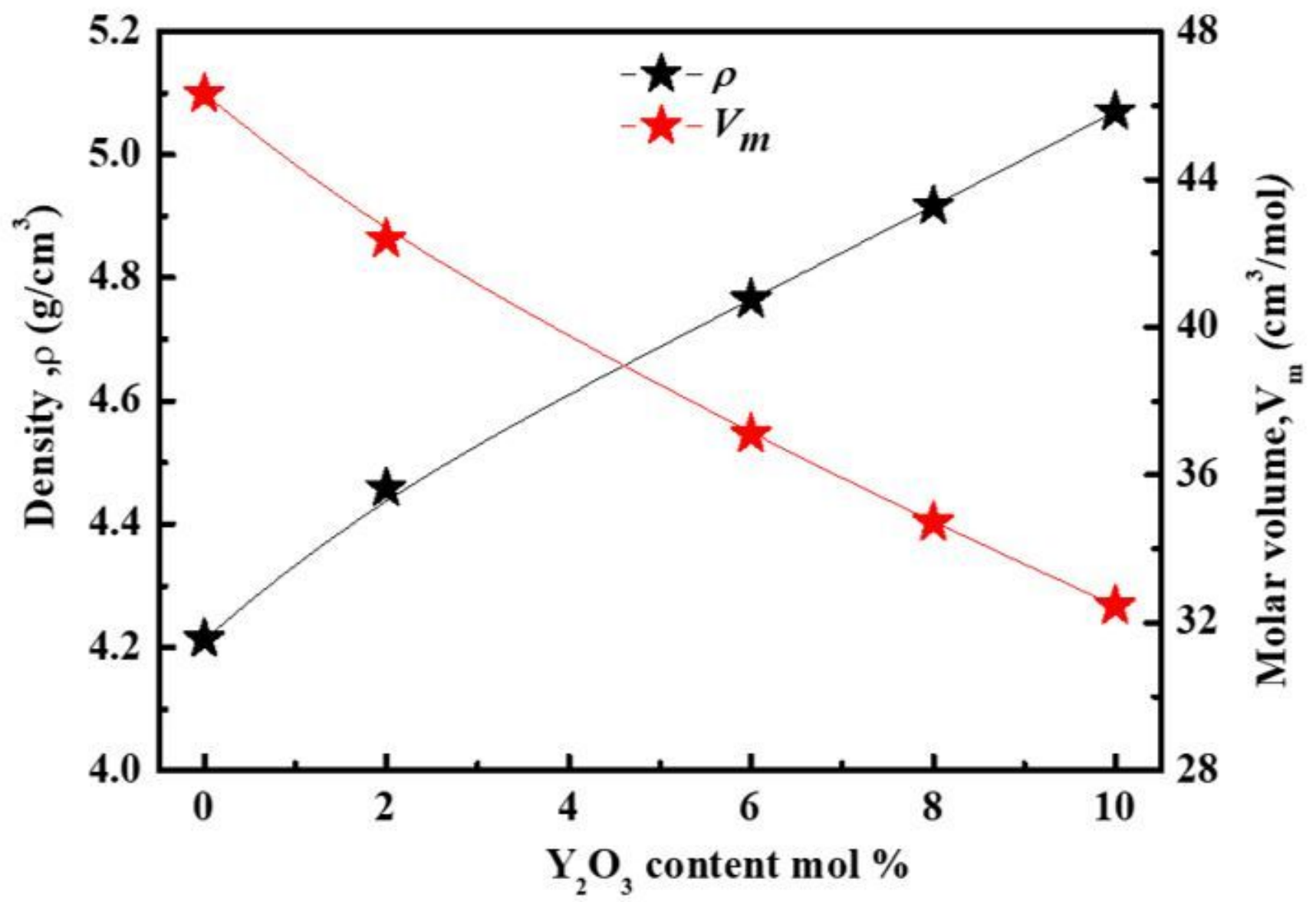

Figure 2

Density and molar volume of the prepared samples versus Y2O3 concentration in mol \%. 


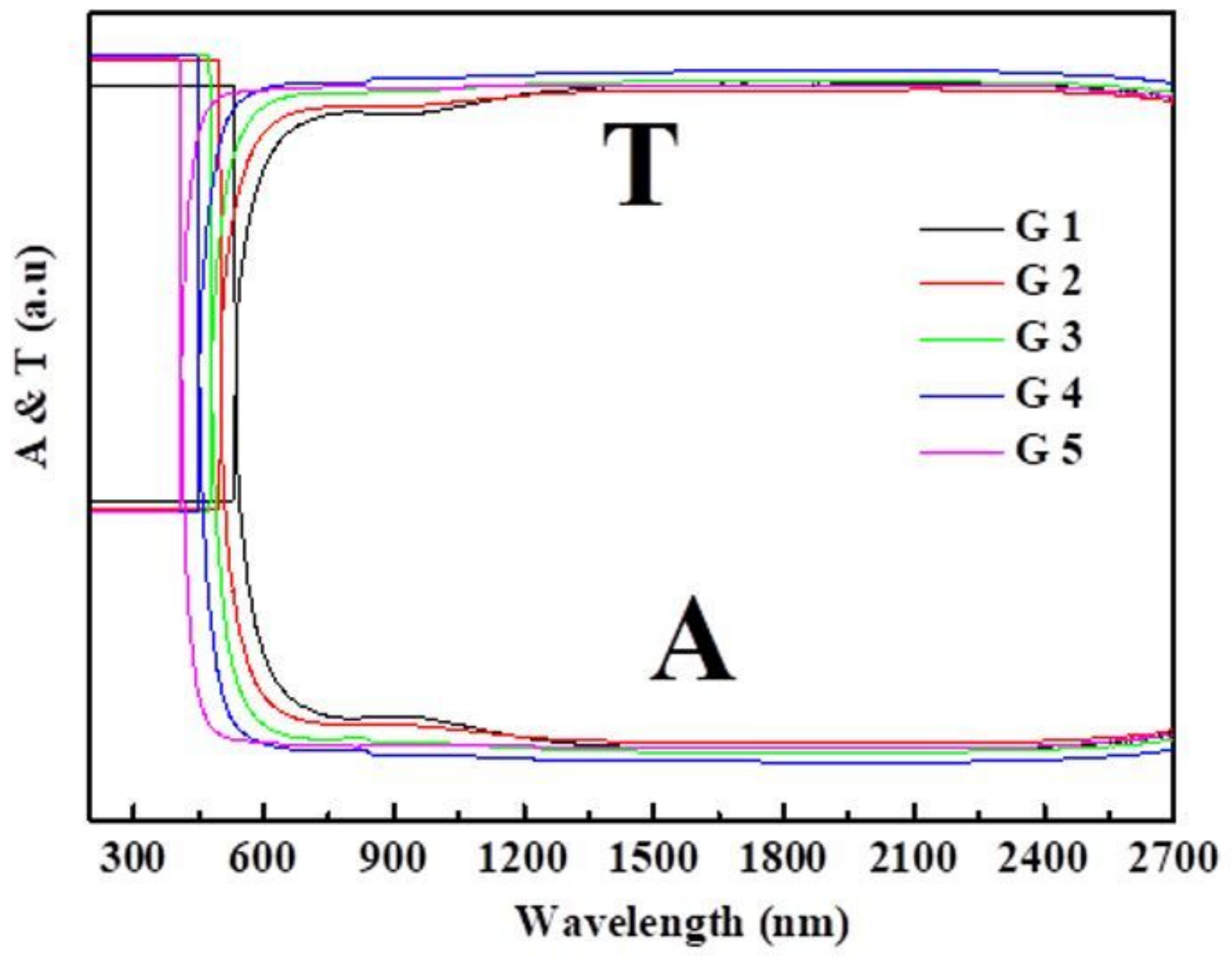

Figure 3

Optical absorption spectra of the prepared glasses 


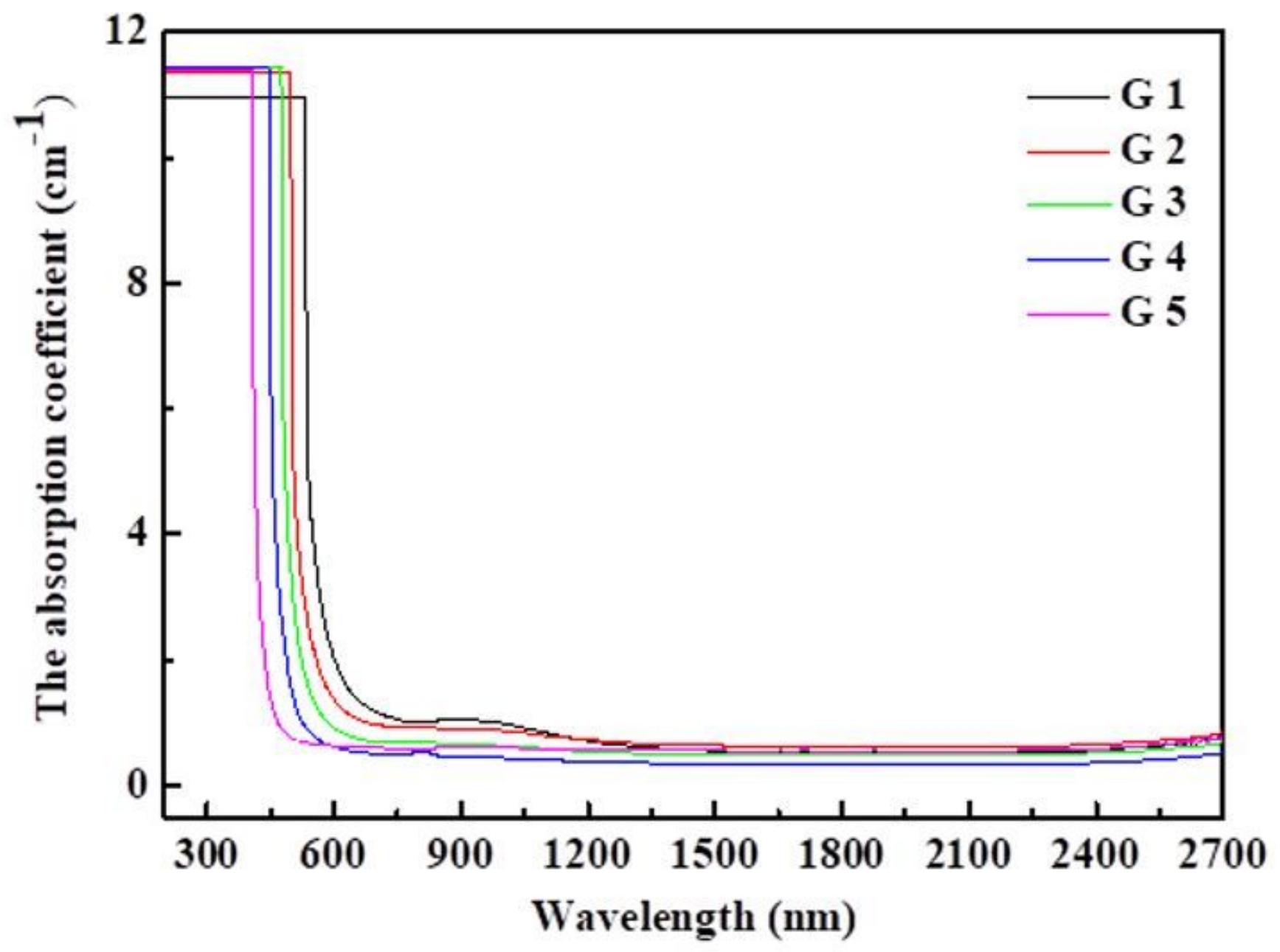

Figure 4

The absorption coefficient of the prepared glasses 


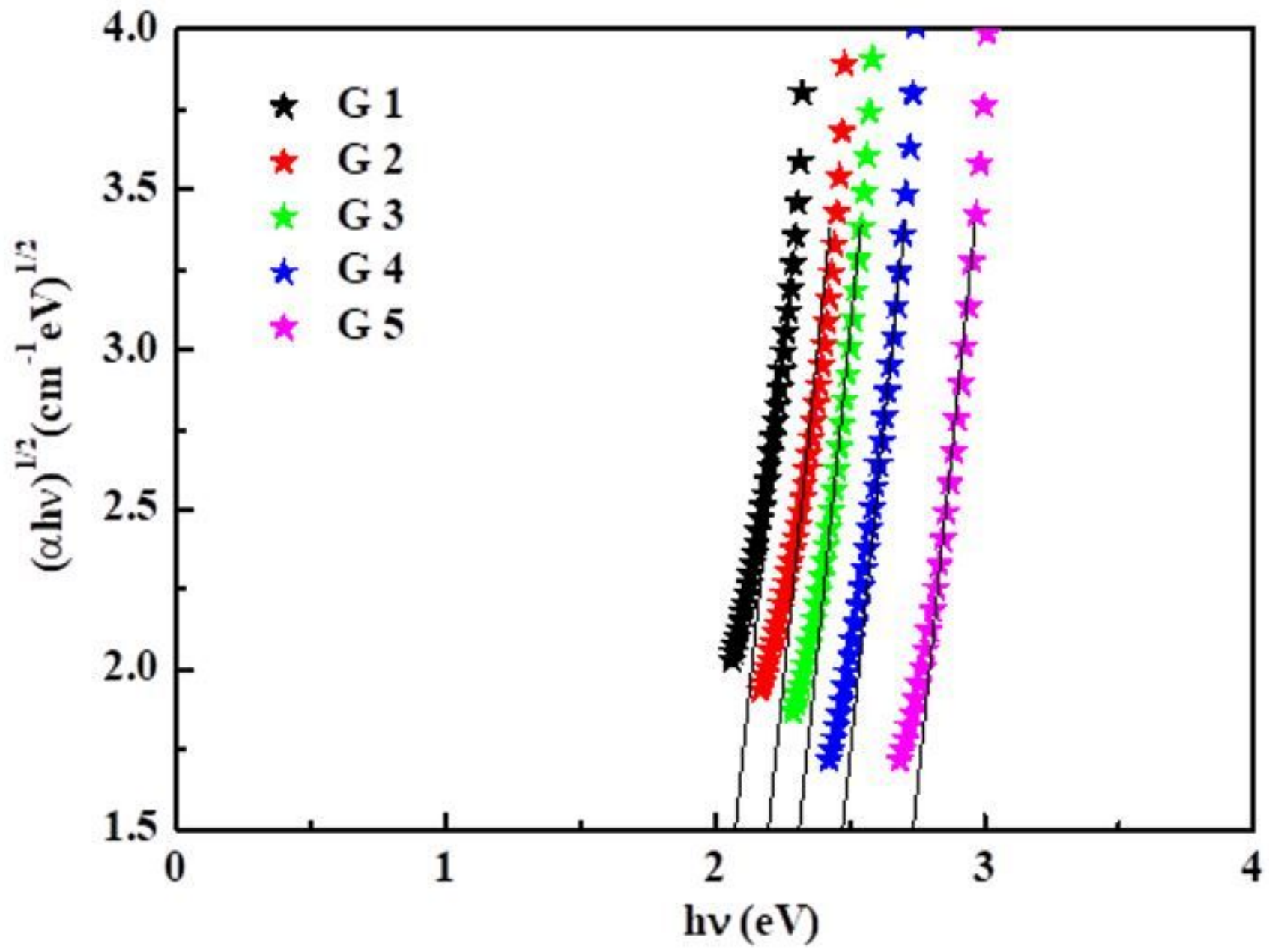

Figure 5

Variation of (ahv) 1/2 as a function of (hv) for studied glasses. 


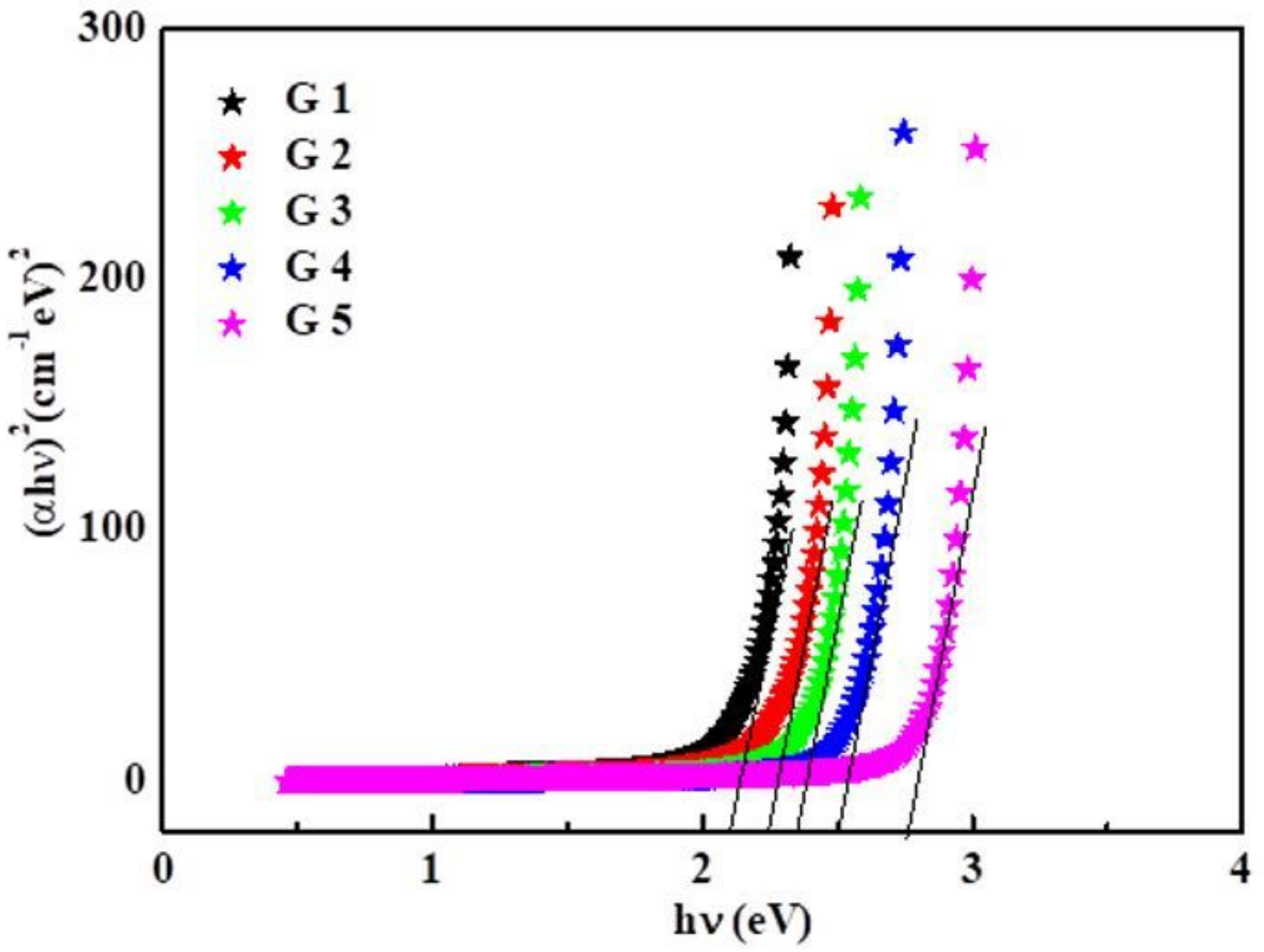

Figure 6

Variation of (ahv)2 as a function of (hv) for studied glasses. 


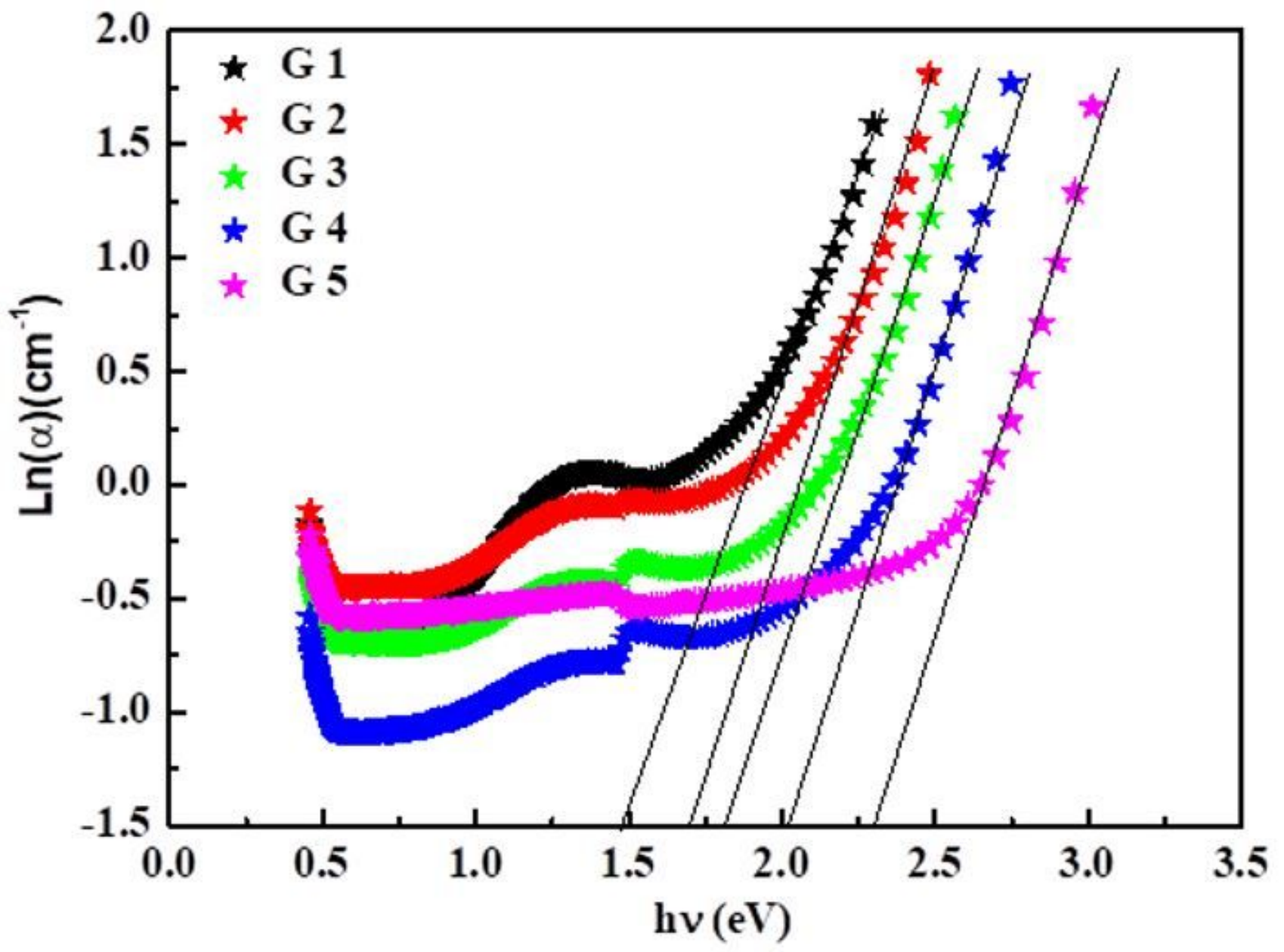

Figure 7

Variation of $\ln (a)$ as a function of hv for the prepared glasses. 


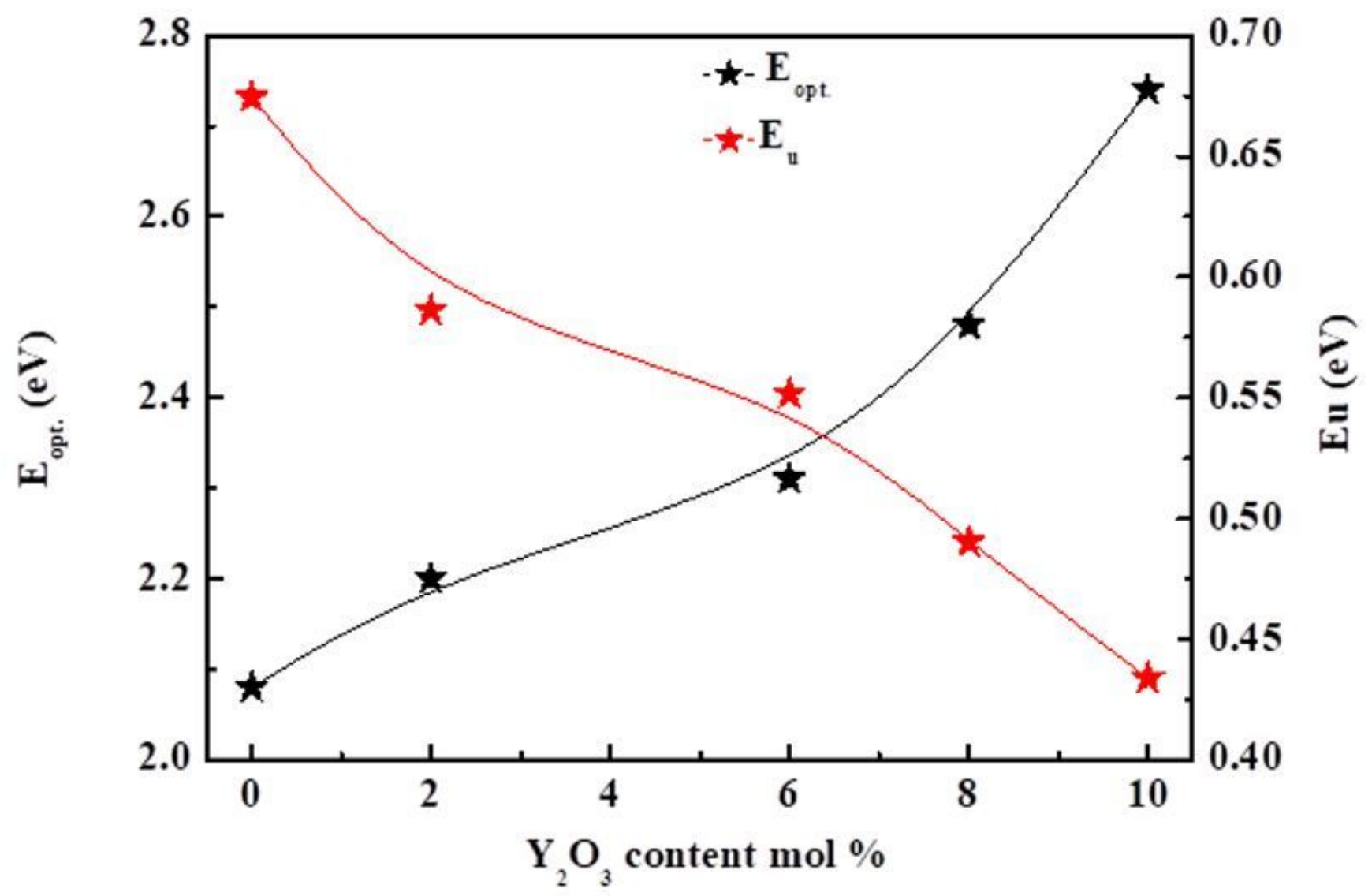

Figure 8

Evolution of bandgap energy (eV) and Urbach energy (eV). 


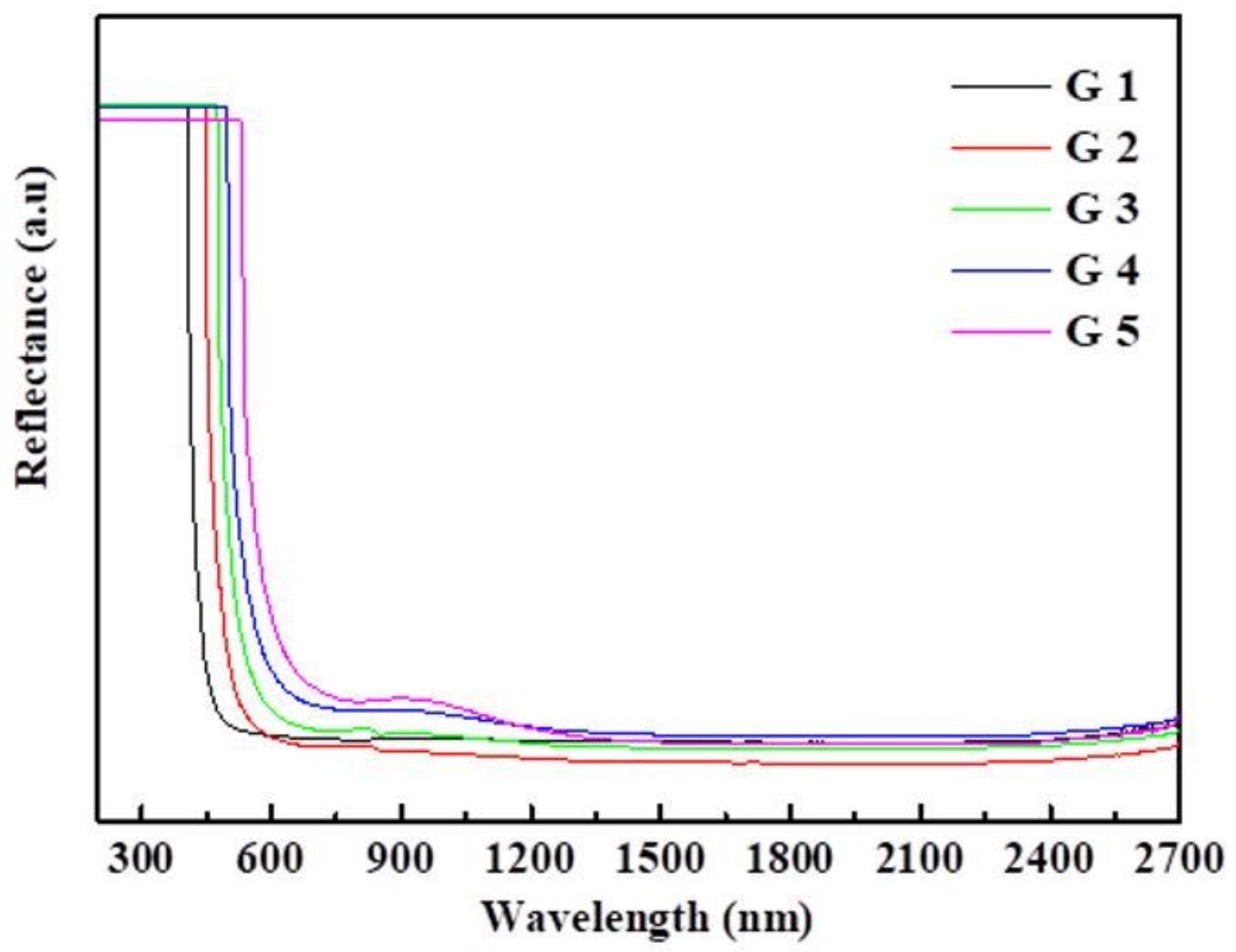

Figure 9

Reflectance spectra of the prepared glasses 


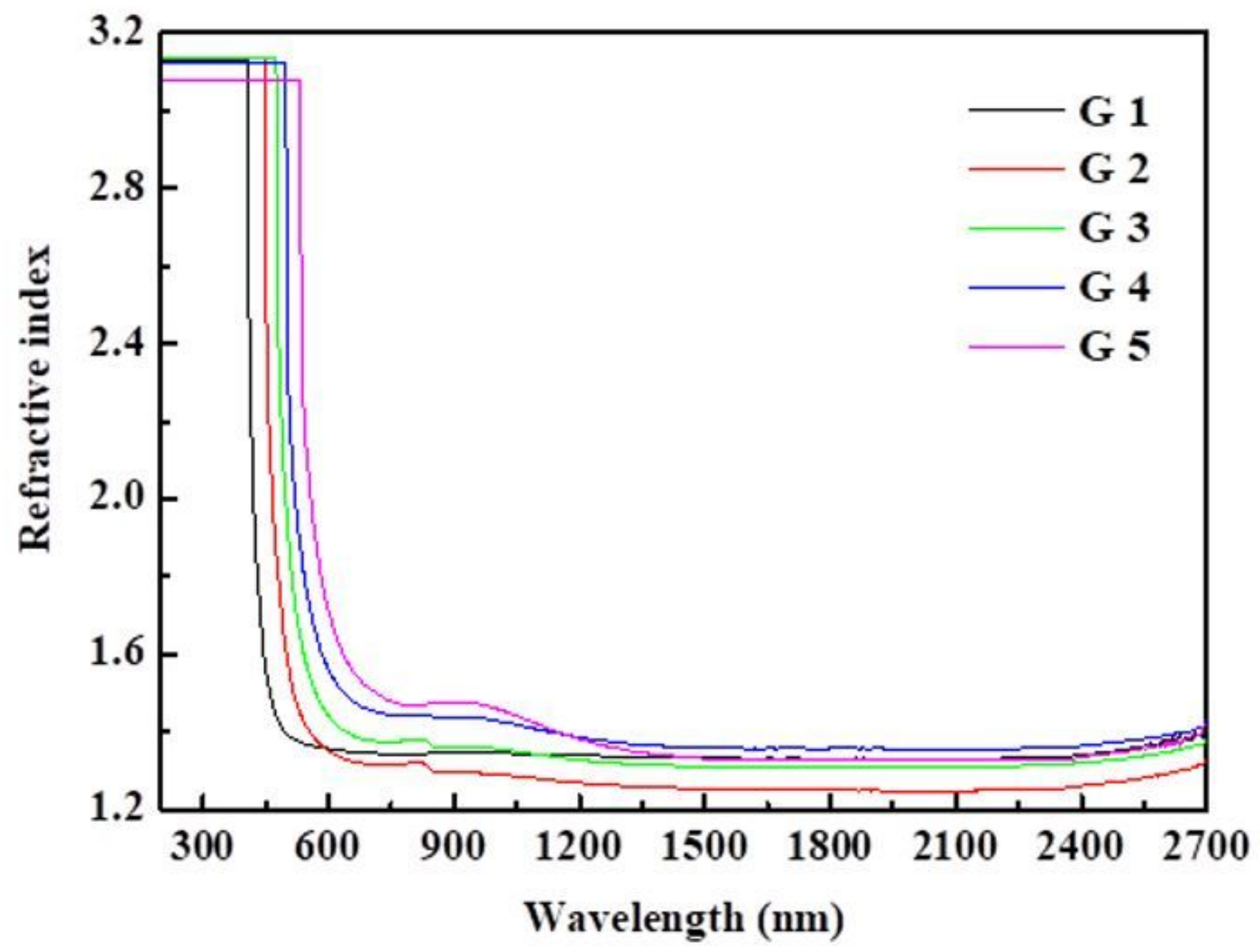

Figure 10

Refractive index of the prepared glasses 


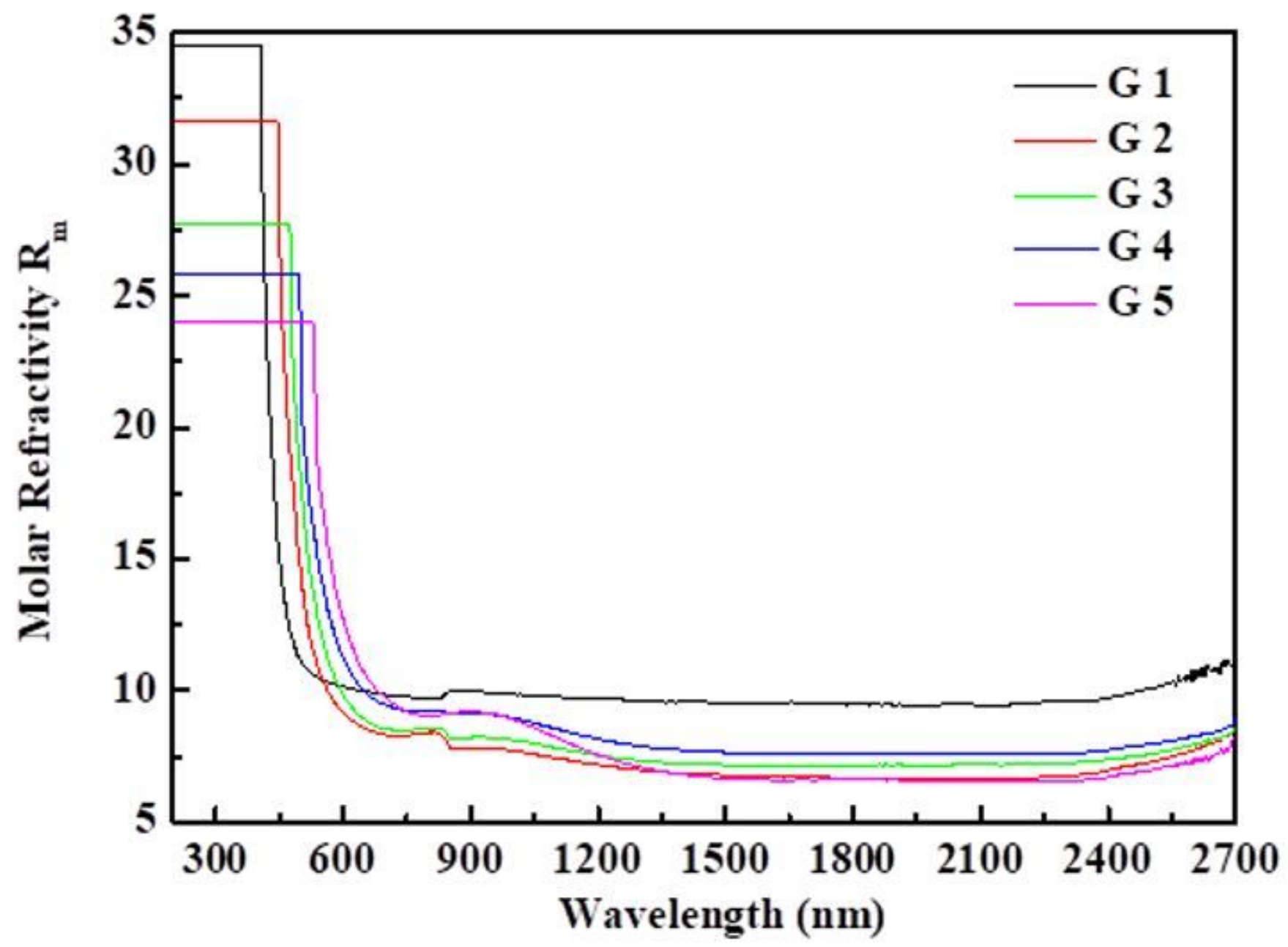

Figure 11

Molar refractivity of the prepared glasses. 


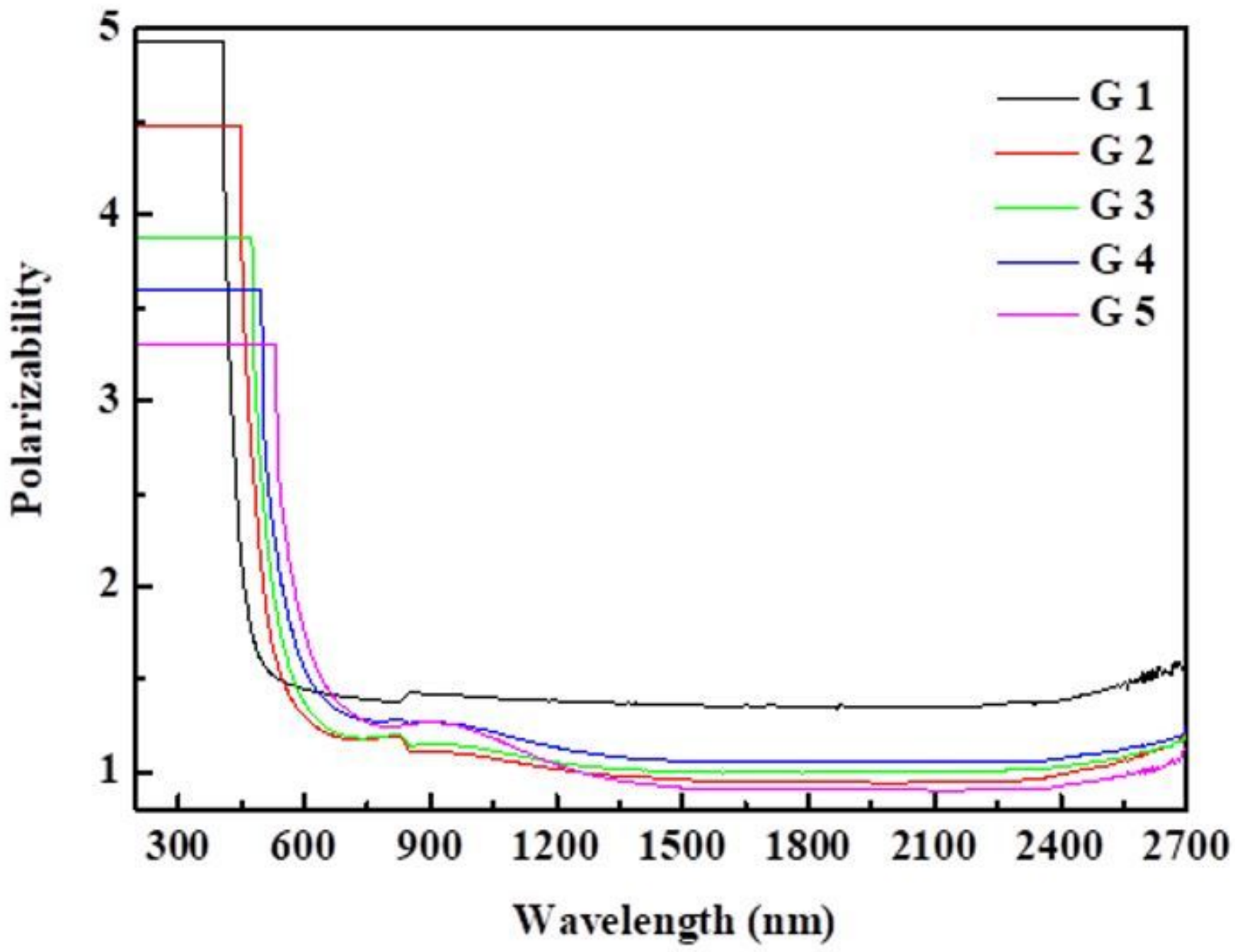

Figure 12

Electronic polarizability of the prepared glasses. 


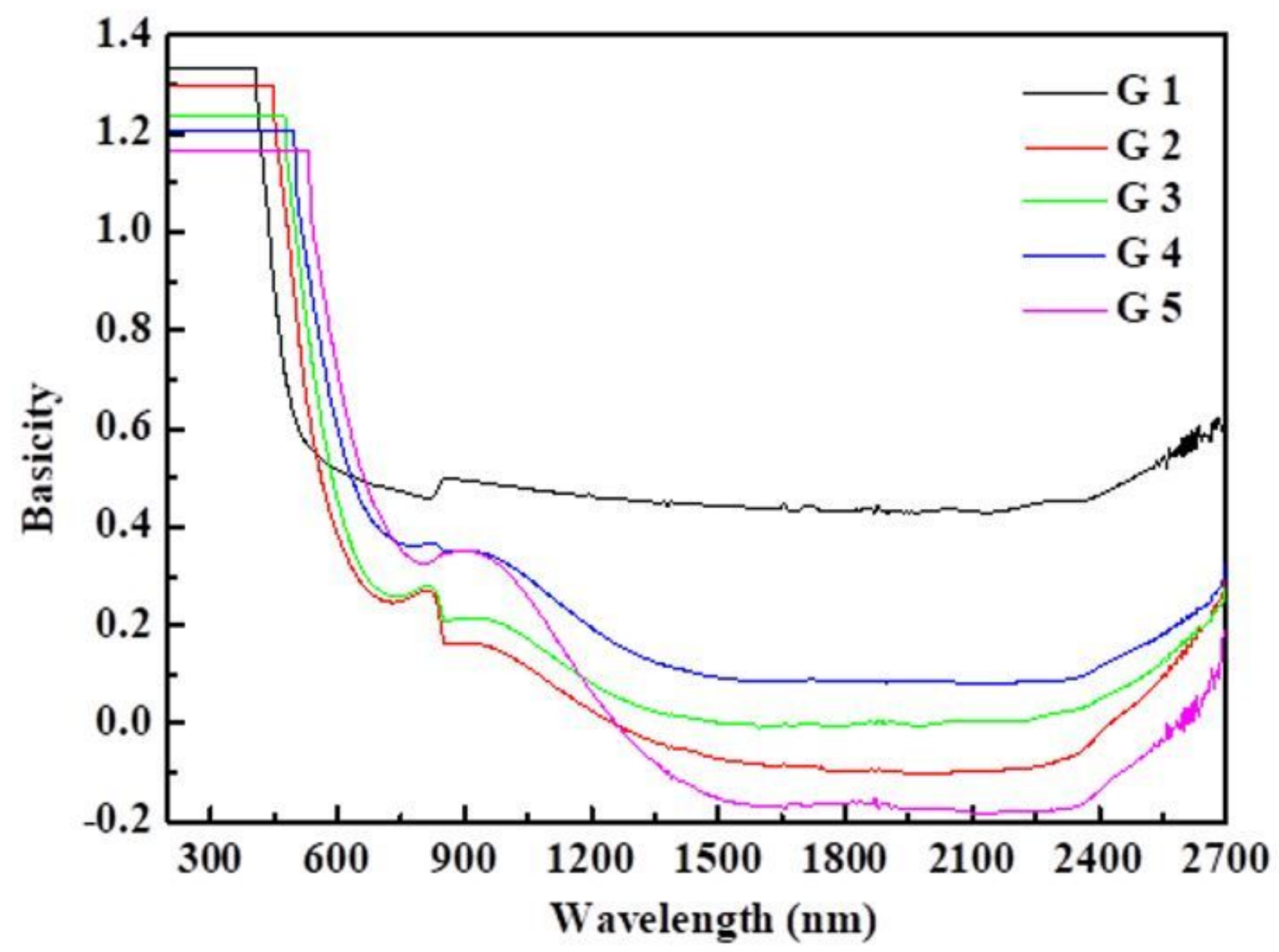

Figure 13

Optical basicity of the prepared glasses. 


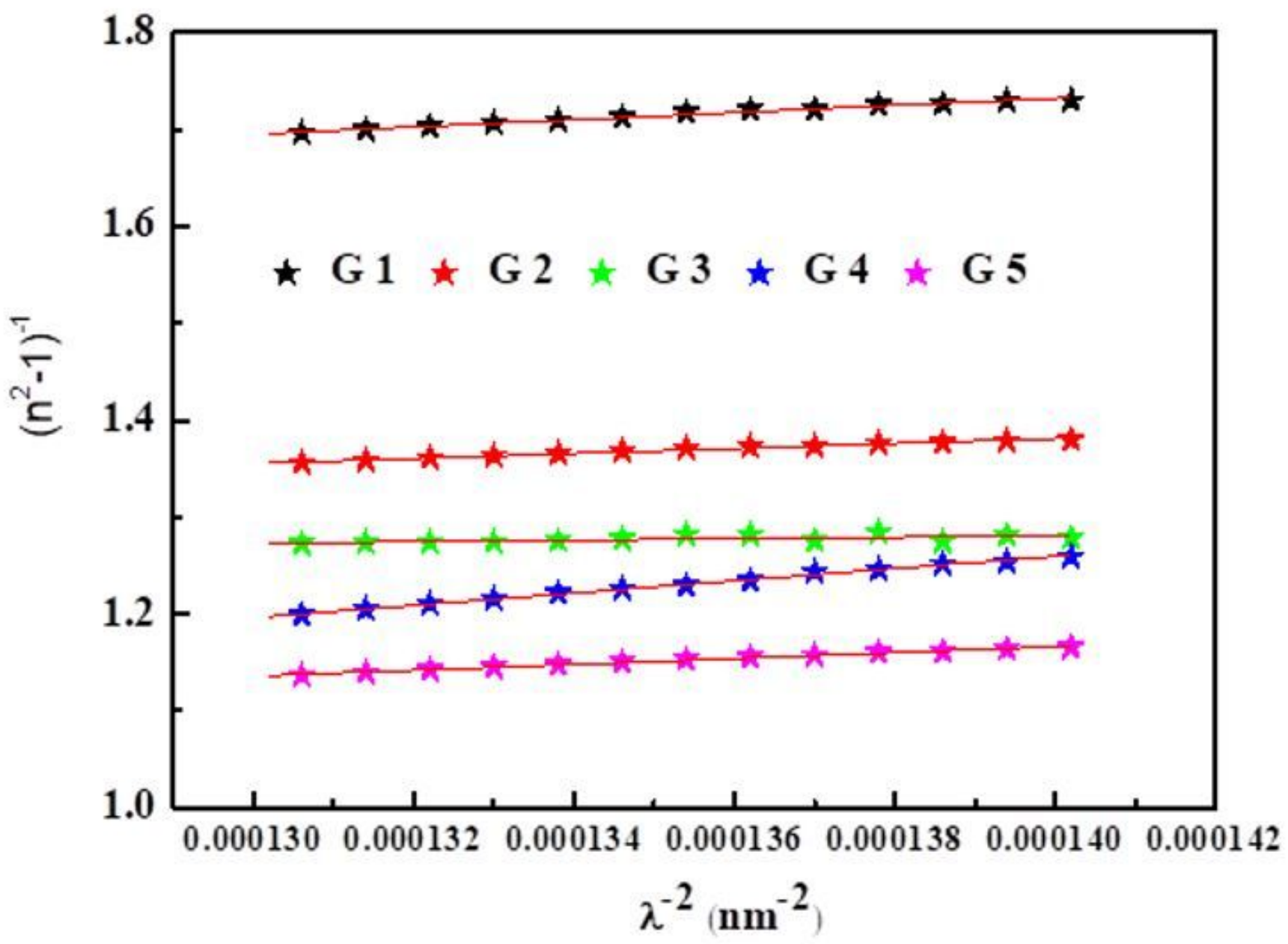

Figure 14

Plots of (n2-1)-1 against $\lambda-2$ of the prepared glasses. 


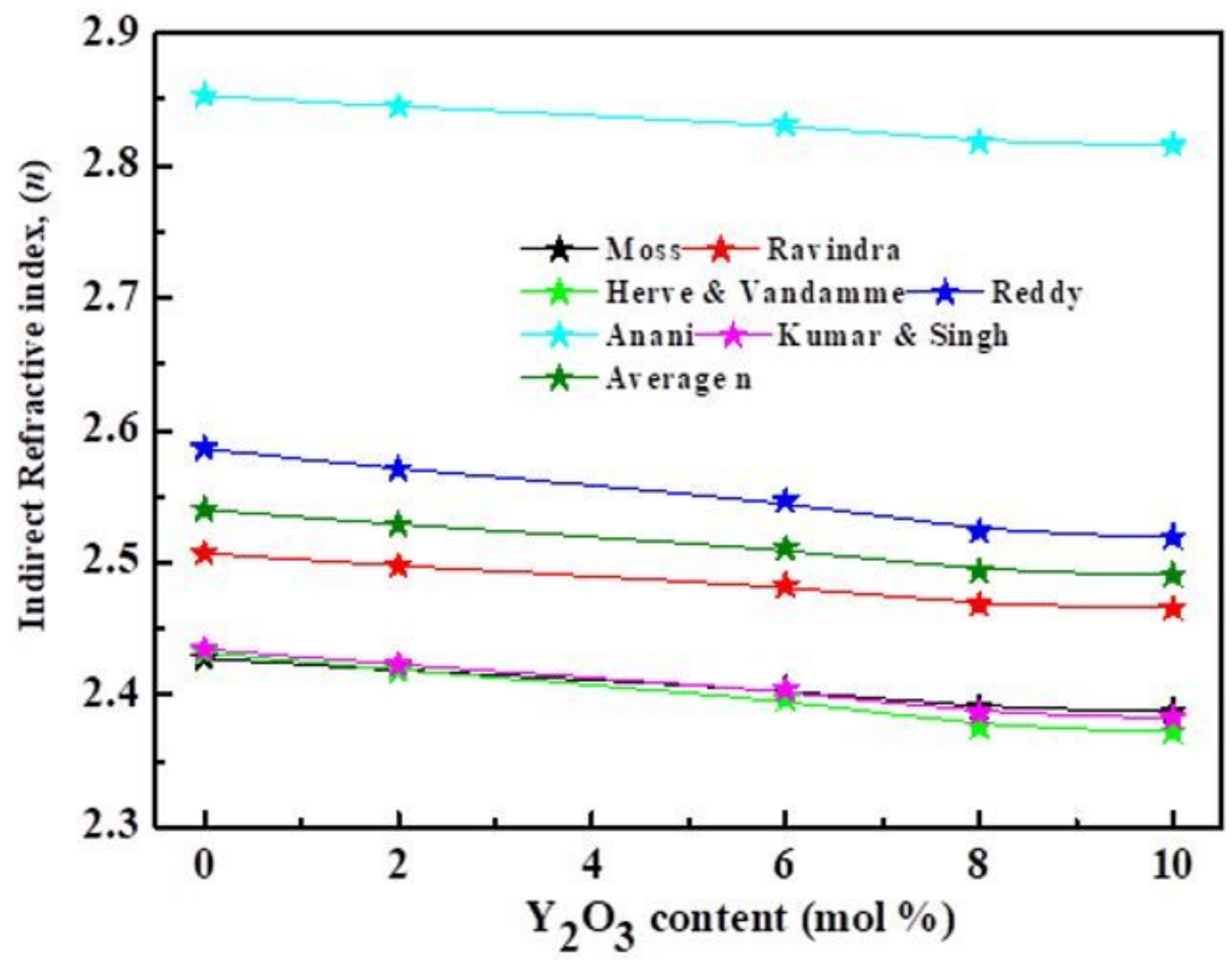

Figure 15

Refractive index of Moss, Ravindra, Herve \& Vandmme, Reddy, Anani, Kumar \& Singh and Average (n) according to indirect bandgap for glass samples. 


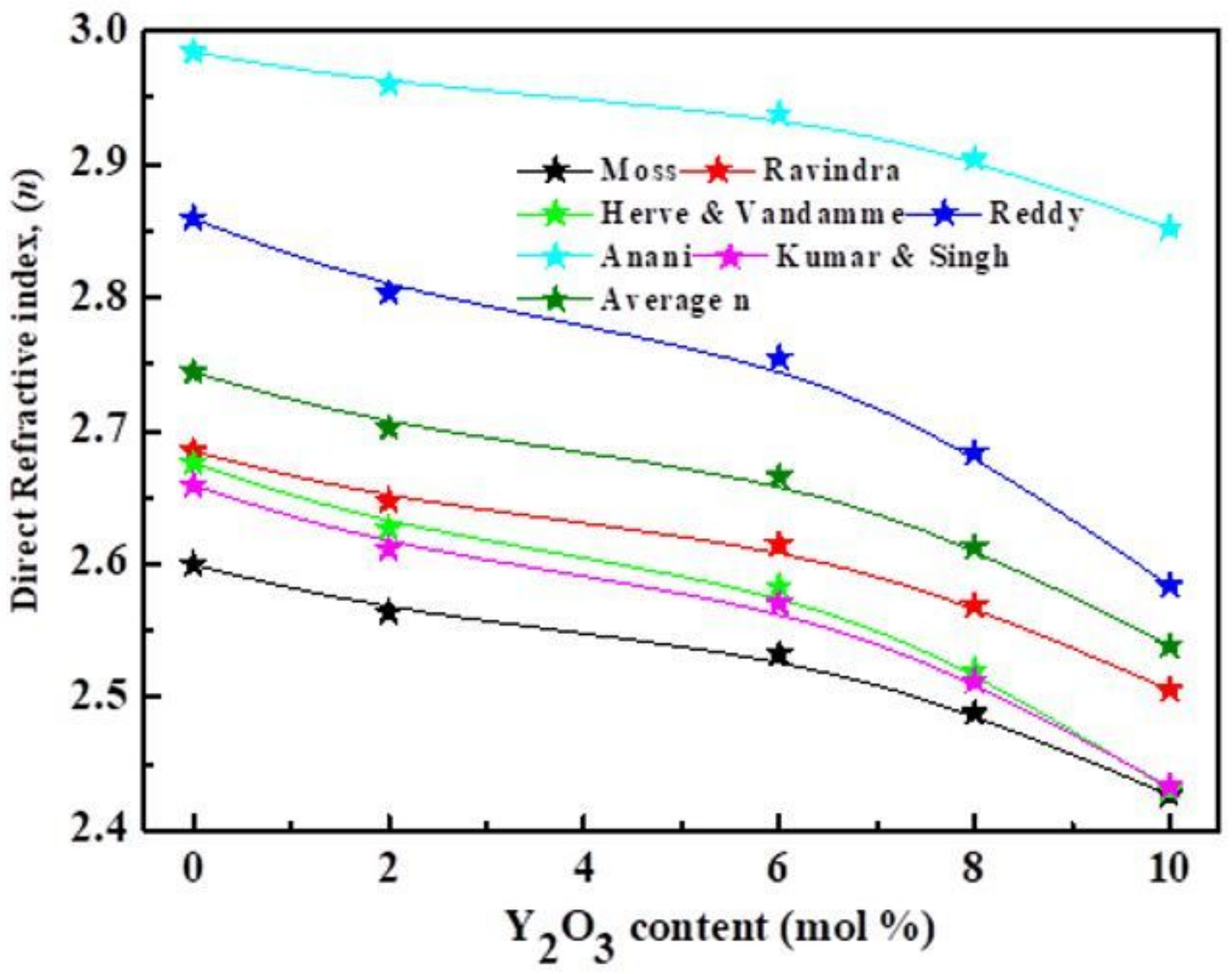

Figure 16

Refractive index of Moss, Ravindra, Herve \& Vandmme, Reddy, Anani, Kumar \& Singh and Average (n) according to direct bandgap for glass samples

\section{Supplementary Files}

This is a list of supplementary files associated with this preprint. Click to download.

- Tables.docx 